\title{
A Mandibular-maxillary Precedence Field in Tooth Eruption
}

\author{
STANLEY M. GARN and B. HOLLY SMITH
}

Center for Human Growth \& Development, The University of Michigan, Ann Arbor, Michigan 48109

\section{J Dent Res (59)9: 1525, September 1980}

In many respects, the dentition behaves in accordance with "field" theory, here defining a "field" as an area of statistical communality, as first introduced with respect to crown size by Butler (Proc Zool Soc 109:1-36, 1939). Field theory has since been applied with success to odontogenesis, to calcification and movement, to agenesis, and to tooth emergence (Garn et al., Nature, 200:488-489, 1963; Garn, Nature, 24: 1501-1502, 1966; Burdi et al., J Dent Res, 55: $309,1976)$. It follows, therefore, that relative timing between the jaws and mandibular-maxillary precedence should also demonstrate a field effect, such that a group of teeth in the mandible or maxilla is systematically advanced or retarded relative to their opponents. To test this possibility we explored mandibular-maxillary precedences in a total of 160 boys and girls in the University of Michigan Longitudinal Series using serial cast data (Moyers et al., Standards of Human Occlusal Development, Ann Arbor Center for Human Growth, 1976). Attention was given to the relative timing of $P_{1}$ and $P^{1}$ and $P_{2}$ and $P^{2}$, as well as those cases where emergence was more nearly synchronous. Each participant was categorized as mandibular precedence, maxillary precedence, or indeterminant (i.e., bunched), leading to a total

Received for publication January 29, 1980

Accepted for publication March 28, 1980

This study was supported in part by grant number DE 03610 from the National Institutes of Health. of nine categories in all. The question was whether mandibular or maxillary precedence of P1 was associated with mandibular or maxillary precedence of $\mathrm{P} 2$, which could not be ascertained by correlational methods or by simple enumeration of frequencies (Israel et al., Arch Oral Biol, 13:239241, 1968).

As shown in the Table, there is a strong association in the direction of jaw precedence for both $P_{1}$ and $P_{2}$. Boys and girls with mandibular precedence of $\mathrm{P} 1$ tend toward mandibular precedence of $\mathrm{P} 2$ and vice versa. Participants with the (rarer) maxillary precedence of $\mathrm{P1}$ tend toward maxillary precedence of $\mathrm{P2}$. The association also holds for indeterminant or "bunched" emergence precedences. Overall, the association is highly significant by the Chi-squared test $\left(\chi^{2}=34.7\right.$ with 4 degrees of freedom, $p<.001)$. P1 and P2, therefore, constitute a field with respect to mandibular precedence, maxillary precedence, or more nearly synchronous emergence.

Clearly, there is an emergence field governing relative timing of opponents in the two jaws, just as there is an emergence field linking the relative emergence timing of teeth within jaws (Garn and Smith, $J$ Dent Res, in press). With these new additions we can now extend the list of known and verified fields to include individual teeth, morphological classes, opponents and antimeres, jaws, and distance, as well as fields surrounding hypoplastic or missing teeth. This model, showing the systematic nature of inter-jaw precedence, extends our knowledge of emergence timing to include relative timing of opponents and the ability to predict which of a pair of opponents will emerge first.

TABLE

ASSOCLATION IN MAXILLARY-MANDIBULAR PRECEDENCES

\begin{tabular}{lccc}
\hline & \multicolumn{3}{c}{ Precedence of $\mathbf{P 2}$} \\
\cline { 2 - 4 } \multicolumn{1}{c}{ Precedence of $\mathbf{P} 1$} & $\begin{array}{c}\text { Maxillary } \\
\mathbf{P}^{2} \mathbf{P}_{2}\end{array}$ & $\begin{array}{c}\text { Tied } \\
\left(\mathbf{P}^{2} \mathbf{P}_{2}\right)\end{array}$ & $\begin{array}{c}\text { Mandibular } \\
\mathbf{P}_{2} \mathbf{P}^{2}\end{array}$ \\
\hline Maxillary precedence $-\mathrm{P}^{1} \mathbf{P}_{1}$ & 4 & 7 & 1 \\
Uncertain or tied $-\left(\mathbf{P} 1 \mathbf{P}_{1}\right)$ & 17 & 44 & 22 \\
Mandibular precedence $-\mathrm{P}_{1} \mathbf{P}^{1}$ & 2 & 21 & 46 \\
Chi-squared $\left(\chi^{2}\right)$ & & & $35^{*}$ \\
\hline
\end{tabular}

*Coefficient of contingency equals 0.42 . 